\title{
Behavior of Adhesion Forces of the Aqueous-Based Polyurethane Adhesive Magnetically Conditioned
}

\author{
Wanderley da Costa ${ }^{1 *}$, Edith MM Souza ${ }^{2}$, Leonardo GA Silva ${ }^{3}$ and Helio Wiebeck \\ ${ }^{1}$ Department of Metallurgical Engineering and School of Polytechnic, USP, Sao Paulo, Brazil \\ ${ }^{2}$ Department of Metallurgical and Materials Engineering of the Polytechnic School, USP, São Paulo, Brazil \\ ${ }^{3}$ Centro Technology Radiation, IPEN, São Paulo, Brazil \\ ${ }^{4}$ Departament of Metallurgical and Materials Engineering of the Polytechnic School, USP, São Paulo, Brazil
}

\begin{abstract}
This research presents a new proposal to water based adhesives manufacturing process, utilizing magnetic conditioning. Using this technique it is possible to increase the adhesion capacity between the adhesive and the substrate. The formulation proved to be efficient after the magnetic conditioning and without reactivation which also generated a significant alteration of the viscosity which was $350 \mathrm{mPa}$.s to $1100 \mathrm{mPa} . \mathrm{s}$, without the necessity of the addition of any other product as thickener. If we compare the same adhesive formulation, with magnetic conditioning and without reactivation and an adhesive without magnetic conditioning and with reactivation, the increase of adhesion capacity was $42.11 \%$, in the magnetically conditioning. When we verify the shear stresses in adhesive without reactivation, without magnetic conditioning and irradiated at $15 \mathrm{kGy}$ we found an average of $3.29 \times 10^{5} \mathrm{~Pa}$ in the shear stresses, that is 2.16 times lower, compared with the average value found in the test specimens, magnetically conditioned, without reactivation, which was $7.11 \times 10^{5} \mathrm{~Pa}$. If the non-ionizing radiation dose of $25 \mathrm{kGy}$ passes, the shear stresses decrease considerably, regardless of the process, with or without magnetic conditioning has the consequence of breaking of the bonds of the polymeric matrix with the test specimens interface.
\end{abstract}

Keywords: Polyurethane; Ionizing radiation; Magnetic conditioning

\section{Introduction}

It is difficult to imagine a product in our home, in industry, transport or any other place that does not use any adhesive or sealant. Based on this fact, it can be affirmed that the adhesives and sealants are present in all segments of the world economy and for this reason have great significance. Since remote times there have been evidences of the use of substances with adhesive capacity, such as animal substances, asphalt material, resin trees, among others. With the development of organic chemistry, new materials and methods have arisen ushering in the production of synthetic adhesives. In order to improve productivity, new processing techniques and equipment have been contributing to a production performance in terms of more competitive operating costs. Currently, the choice of adhesive to promote the union between substrates, rather than mechanical joining methods have some advantages in the use of materials of various thicknesses; absorbing vibrations, sealing capacity and mechanical resistance, thus minimizing the problems of fatigue and decreasing the specific mass of the material, as well as reducing the production costs. Some challenges still exist concerning the use of adhesives, such as need to prepare the substrate, limited service temperature, lower mechanics forces and toughness in relation to metal joints, that do not allow dismounting when the joint is produced by electric welding. Adhesives and sealants are usually formulated based on the following substances: polymeric matrix, fillers, pigments, stabilizers, plasticizers and other additives that are required to confer specific characteristics to the final product. The processes used may involve simple mixtures, as well as sophisticated known as copolymerization processes [1-3].

With so many choices of materials to be adhered, it is necessary to list a few factors of choice for a particular type of adhesive. The adhesive should wet the surface where it will be applied; If the surface is difficult to wet, it should be prepared to receive the adhesive. The adhesives should be more rigid than the substrate, so there would be no stress concentration in adhesives. After the adhesive drying and hardening, the glue joint must resist environmental and mechanical conditions. Both the adhesive, and the method of application thereof, must have low-cost. Other factors that should be highlighted when considering the formulation and choice of adhesives, are the adhesion capacity and cohesion capacity. The polymeric matrixes and some additives should promote or increase these characteristics. Regarding the adhesion, it is understood that this is the result of forces between the adhesive and the substrate, whereas cohesion is the result of forces between the molecules within the adhesive, i.e., the interaction between the components of the formulation. The adhesive studied in this research, called polyurethane, has already been in the market in water base since 2000. Nowadays, the adhesive industry goes through a rereading, seeking high efficiency and substances in compliance with the environmental and market requirements. Studies on the replacement of organic solvents are being intensified and currently $58 \%$ of the adhesives already produced use water as solvent [4].

Analyzing this scenario, it can be said that the water-based polyurethane adhesive still requires better results for shear stresses and resistance to hydrolysis. Although there are several formulations in the market, some applications that use adhesives on solvent-based version, mainly due to its properties of open time and adhesion capacity, are used in specific applications in the automotive industry. Based on this fact, this research was held in order to innovate the concept of formulating water based polyurethane adhesives, based on a new technical proposal of the adhesive production technique using the advanced technologies such as magnetic conditioning [5-10] for the production that adhesive. This is designed to improve the properties of the shear stresses of the cured adhesive as much under ambient conditions as in exposure to non-ionizing irradiation in the above-mentioned processes [11].

*Corresponding author: Wanderley da Costa, Department of Metallurgical Engineering and School of Polytechnic, USP, Sao Paulo, Brazil, Tel: +5511991235550; E-mail: wandher3@usp.br

Received October 06, 2016; Accepted October 21, 2016; Published October 30 2016

Citation: Costa W, Souza EMM, Silva LGA, Wiebeck H (2016) Behavior of Adhesion Forces of the Aqueous-Based Polyurethane Adhesive Magnetically Conditioned. Mod Chem Appl 4: 190. doi: 10.4172/2329-6798.1000190

Copyright: @ 2016 Costa W, et al. This is an open-access article distributed under the terms of the Creative Commons Attribution License, which permits unrestricted use, distribution, and reproduction in any medium, provided the original author and source are credited. 


\section{Water-based systems}

The water-based systems are dispersions of polymeric matrixes that may be polyurethane or any others, which, in turn, may be used practically on the same conditions of the solvent-based systems, representing a better alternative and ecologically perfectly viable. The long and positive experience of the industry with the solventbased adhesives, arose several questions in the market regarding the advantages of the technology of water-based adhesive, which uses water as a solvent. It should be noted that the water based adhesives polyurethane are free from odor, environmentally friendly and safe. The demand of this market grows every year in relation to the solventbased polyurethane adhesives [12].

\section{Polyurethane adhesive}

Polyurethane adhesives are derived from raw materials polyol and isocyanates, such as described in the general equation Figure 1, because of its molar mass, have low open time, which requires thermal reactivation step. These adhesives have very good initial adhesion, and are easy to apply. It is noted that the water-based polyurethane adhesive formulation provides a uniform and thin thickness application, resulting in an excellent final bonding. They can be used in wide variety of substrates, they can be welded on themselves upon application of pressure and have high cohesive efficiency. They are flexible, have a solid tenor between 15 to $20 \%$ when solvent-based is between 40 to $55 \%$ in water-based. They are widely used in the footwear, belts and handbags industries. This family of adhesives, denominated contact adhesives must be applied to both substrates. To carry out the union, it is mandatory to wait the solvent evaporate (water) or perform the thermal reactivation for bonding both substrates. Shortly after this contact a 110 psi pressure is performed on the glued sets [13-22].

In traditional formulations, both the solvent-based and the waterbased adhesives, must be reactivated so that adhesive cohesive forces are intensified. The commercial water-based formulations have high adhesion capacity so they are able to resist the average shear stresses in $3.92 \times 10^{5} \mathrm{~Pa}$. This value is lower than that observed in tests with solvent-based polyurethane adhesives, at the average value of reference which is $4.90 \times 10^{5} \mathrm{~Pa}$. To solve the difference between the shear stresses, it is necessary to find innovative alternatives regarding the choice of raw materials used in adhesive preparation, as well as to introduce process stages of production, as it was done in this research work with the magnetic conditioning [1,2,15-17] (Figure 1).

\section{Water based adhesive polyurethane}

Traditional water-based adhesives are composed of polymeric matrixes, antioxidants, catalysts and other additives to grant ideal
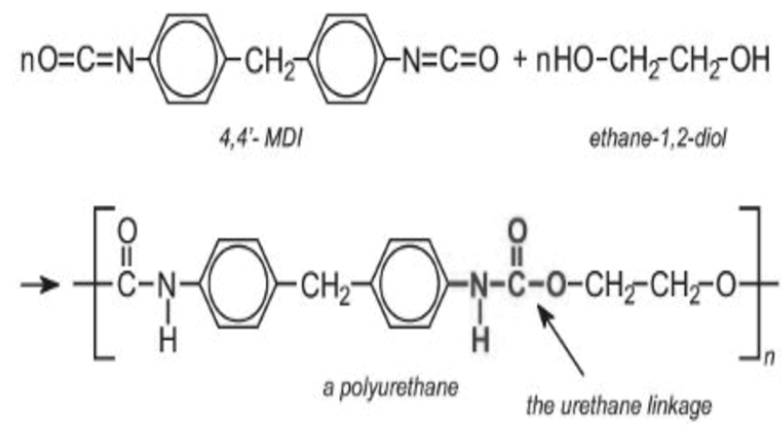

Figure 1: General chemical structure of polyurethane. properties for their application. In the water-based formulation, the polymeric matrix, normally, is an emulsion in water. In this formulation, the water present in the emulsion must be evaporated to proceed to the bonding of materials. However, there are currently polymeric matrixes that can be used in conjunction with catalysts called blocked, which are substances that remain inactive at room temperature, and only in the presence of an adequate amount of heat are unlocked and from this point begins the curing process, resulting in the development of the mechanism of cross-reactions. It requires special care on the validity of this product, which is shorter compared to solvent-based, as its validity ranges from six months to one year depending on the formulation and its storage conditions that cannot be in places with temperatures above $50^{\circ} \mathrm{C}$ and below $5^{\circ} \mathrm{C}$.

A relevant factor, to develop water-based adhesives resides in the possibility of not depending too much on the solvent-based adhesives, due to its advantages. Besides the fact of reducing the use of organic solvents in the formulations of solvent-based polyurethane adhesives. It can also reduce the use of other substances such as, for example, phthalates, flame retardants, pyrogenic silica and other additives, which has the purpose of improving the adhesive properties [13,14,18-20].

\section{Production of water-based adhesive polyurethane}

Normally to produce water based adhesives water dispersions of polyurethane and other substances which are conveniently mixed are used in the following proportions [17-20]. Main Polyurethane Dispersion: $90-98 \%$ in weight, Antioxidant or auxiliary additives 0.1 to $2 \%$ in weight.

Once formulated, the water based polyurethane adhesive can be magnetically conditioned as described in the following item.

\section{Magnetic conditioning of aqueous solutions}

The proposal of using the process of magnetic conditioning after the formulation of a water-based adhesive, lies in the fact that there are studies reporting evidence such as $\mathrm{PH}$ changes, electrical conductivity, surface stress, magnetic susceptibility and ionization constant. All this generates a reversal of the spins of electrons, affecting directly the hydrogen bonds and changes in salt and crystal structures of the solutions that were subjected to this process. In other words, in the water-based adhesive case, it is possible to obtain some important changes in the properties of magnetically conditioned adhesives [5$9,14]$. As this is an unprecedented research work for polyurethanes aqueous based and there were no specific studies explaining how the action of magnetic fields can change the properties of the adhesives water-base polyurethane, especially how the shear stresses behave in interface of materials, until such research. Magnetic conditioning of water-based solutions as presented in the literature, organizes the molecular structures facilitating their ordination in a predefined direction, thus positively interfering in its viscosity. This improves the applicability of the product and increases the bonding strength on the surface of the substrates. With the increase of these properties, the adhesive improves its efficiency on the substrate surface and the formed film, not allowing the adhesive percolation into the substrate, thereby improving the efficiency of the adhesion conditions. Thus, the wettability or moistening can be defined as the measure of the contact angle between the adhesive and the adherent (substrate). The adhesion capacity is closely related to the spreading of the adhesive due to its surface tension at the interface of the substrate. When the liquid portion of the adhesive, solvent (water) is evaporated, the disposal of the solid part on the surface and its regularity in the formation of the film, will contribute to a better result in shear stresses. Adhesion 
is understood as a result of the action of forces opposing separation of adhesive molecules on the surface of the substrate, i.e., the ratio of attraction between different substances of the entire system resulting in an intermolecular force. This adhesion is often caused by molecular interactions between the adhesive and substrate and not necessarily by chemical bonds.

Cohesion is different of adhesion, because involves forces between the adhesive and the substrate and the cohesion, it is the attraction between the substances that makes the adhesive formulation, that is, it refers to the union of molecules of the same substance. This is defined as an action of forces that oppose the separation of molecules of a homogeneous body. This technique contributed to the realization of a research [10] on which it was reported the use of magnetic conditioning with water based polychloroprene adhesive, obtaining excellent results in the properties of shear stresses [16].

\section{Application after conditioning magnetic}

After the magnetic conditioning process the water-based polyurethane adhesive may be catalyzed in a proportion of 3 to $5 \%$, with Desmoldur DN (hexamethylene diisocyanate, HDI), according to the formula and applied by brush or spraying process. As already mentioned, it is necessary the insertion additives, for example, stabilizers and antioxidants in order to provide stability of the formulation during storage, to ensure its use, thereby protecting against aging and discoloration.

In another study in the adhesive area, non-ionizing radiation was used in adhesive sealant silicone links and butyl mastic. This process has improved the shear stresses in the butyl sealant formulations, whereas the silicon sealant has degraded the entire gluing system. This study was important to verify how the non-ionizing radiations interferes with links of the silicone sealant adhesion and butyl mastic, which according to the shear stresses tests, we were able to understand and to verify the behavior of such products in terms of the adherence [11-16].

\section{Materials and Methods}

The methodology of this research may be defined as a bibliographic, documentary, experimental and comparative research. For this purpose, 8 samples groups were organized: 4 groups containing 25 sets of substrates each one and 4 groups containing 6 sets of substrates each one. The sample groups were designate as follows:

Group 1: Samples in which was applied water based polyurethane adhesive, already formulated, without magnetic conditioning and with reactivation air at the temperature of $60^{\circ} \mathrm{C}$.

Group 2: Samples in which was applied water based polyurethane adhesive, already formulated, with magnetic conditioning and with reactivation air at the temperature of $60^{\circ} \mathrm{C}$.

Group 3: Samples in which was applied water based polyurethane adhesive, already formulated, without magnetic conditioning and without reactivation of heated air.

Group 4: Samples in which was applied water based polyurethane adhesive, already formulated, with magnetic conditioning and without reactivation by heated air.

Group 5: Samples in which was applied water based polyurethane adhesive, already formulated, without magnetic conditioning, without reactivation by hot air and submitted to non-ionizing irradiation dose of $15 \mathrm{kGy}$.

Group 6: Samples in which was applied water based polyurethane adhesive, already formulated, with magnetic conditioning, without reactivation by hot air and submitted to non-ionizing irradiation dose of $15 \mathrm{kGy}$.

Group 7: Samples in which was applied water based polyurethane adhesive, already formulated, without magnetic conditioning, without reactivation by hot air and submitted to non-ionizing irradiation dose of $25 \mathrm{kGy}$.

Group 8: Samples in which was applied water based polyurethane adhesive, already formulated, with magnetic conditioning, without reactivation by hot air and submitted to non-ionizing irradiation dose of $25 \mathrm{kGy}$.

The methodology of this work consisted of the following steps: preparation of the formulation of the water base polyurethane adhesive; magnetic conditioning process; application of the adhesive in the substrates; conduction of tests to determine the shear stresses with and without non-ionizing radiation.

\section{Materials and equipment's}

For carrying out this research work several necessary equipment and materialswere provided by the companies. The list of all materials and equipments is

a) Main polymer matrix Dispercoll $U^{*} 54$ (Anionic high-weight polyurethane dispersion) of Covestro company, batch C41480060, validity October 16, 2015, Brookfield viscosity, LVR model (sp 3, 10 $\mathrm{rpm}$ ) equal to $380 \mathrm{mPa} . \mathrm{s}$, solids tenor (oven $180^{\circ} \mathrm{C}, 15 \mathrm{~min}$ ) equal to $49 \%$; with high crystallization speed, which will provide mechanic strength properties to the adhesive [21].

b) Catalyst Desmoldur $\mathrm{DN}^{\circ}$ (Hexamethylene diisocyanate-HDI catalyst) of Covestro company, batch LDC 1300029, validity December 20, 2015, Brookfield viscosity, LVR model (sp 3,10 rpm) equal to 1,400 $\mathrm{mPa}$.s, solids tenor (oven $180^{\circ} \mathrm{C}, 15 \mathrm{~min}$ ) equal to $99.8 \%$ used as crosslinking, completing the crosslink connections [21].

c) Antioxidant Rhenofit $\mathrm{DDA}^{\circ} 50 \mathrm{EN}$ of Rhein Chemie Rheinau $\mathrm{GmbH}$ company, a substance derived from diphenylamine in water emulsion. Used as an antioxidant to latex compounds and waterbase adhesives. It prevents damage caused by the action of heat and oxygen, in addition to being effective against dynamic crack formation (cracking) caused by oxygen. The concentration of diphenylamine derivative is $50 \%$, batch 0700008972 , Brookfield viscosity LVR model (sp 3,10 rpm) equal to $100 \mathrm{mPa}$.s and its specific mass is $1 \mathrm{~g} / \mathrm{cm}^{3}$ used as antioxidant.

d) PVC substrate, composed of 60\% PVC resin (polyvinyl chloride) with $40 \%$ plasticizer DOP (dioctylphthalate).

e) Instron dynamometer, model 3367, with load cell $30 \mathrm{kN}$.

f) Blower Thermal Steinel', HL 1500 model, air flow 240/400 L/min, power $1400 \mathrm{~W}, 220 \mathrm{~V}$.

g) Magnetic conditioner Hidrolink', CME Model \# 0075.

h) Temperature gauge laser MINIPA', MT 350 model, -30 to $100^{\circ} \mathrm{C}$.

i) Gaussmeter Globalmag, model TLMP-HALL.

j) Soft bristle brush (white).

k) Submersible pump Atman, AT-302 model, flow $450 \mathrm{~L} / \mathrm{h}, 110 \mathrm{~V}$.

l) Mechanical agitators high-torque microprocessor, Q250M1, 110 V model, $100 \mathrm{~W}$, of Quimis company, serial number 13040004 and 14120002 . 
m) Electron accelerator DC model 04/25/1500 JOB 188 Dynamitron company.

n) Precision balance Mettler-Toledo, model ML 4002E with a maximum capacity of $4.2 \mathrm{~kg}$.

o) silicone hoses with $1 / 4$ diameter.

p) 2 L Becker cups.

\section{Preparation of adhesive}

The water based adhesive was prepared with the polymeric matrix Despercoll $U^{\circ} 54$ (batch C41480060) and the antioxidant Rhenofit $\mathrm{DDA}^{\circ} 50 \mathrm{EN}$ (batch 0700008972). Both were weighed out on precision balance Mettler-Toledo (ML model 4002E) as the formulation (Table 1), mixed in mechanical agitator high torque microprocessor for ten minutes at a speed of $50 \mathrm{rpm}$. The amount of formulated adhesive was 3500 grams.

\section{Conditioning process}

Magnetic conditioning process consists on passing the adhesive of two containers (Becker Cup) $2 \mathrm{~L}$, with the help of silicone hoses and the submerged pumps ATMAN (Figure 2), during the time period of three hours under the effect of magnetic field of $0.02 \mathrm{~T}$ (Tesla) using a magnetic conditioner. The measurement of the magnetic field equipment was the Gaussmeter (TLMP-HALL model Globalmag), according to Figure 3.

\section{Experimental procedure}

For the formulation of the water-based polyurethane adhesive, the mixture was held at mechanical agitator of high torque microprocessor, after the weighing of raw materials, according to data presented in Table 1. After the formulation of the adhesive formulation, the resting time

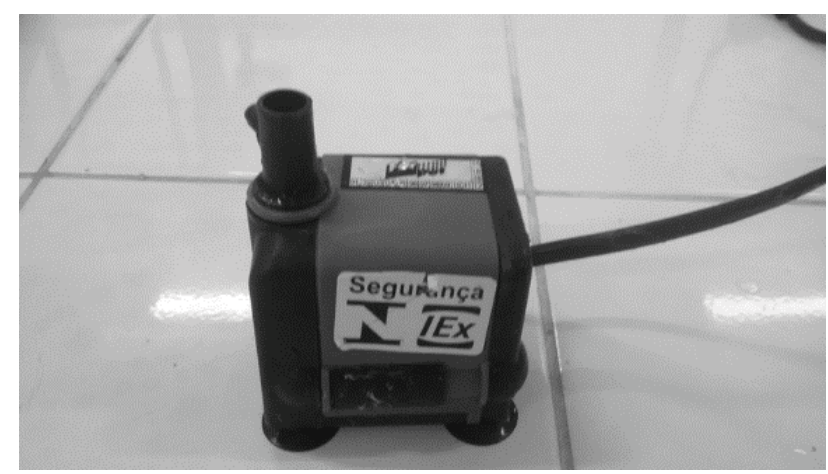

Figure 2: Submersible pump.

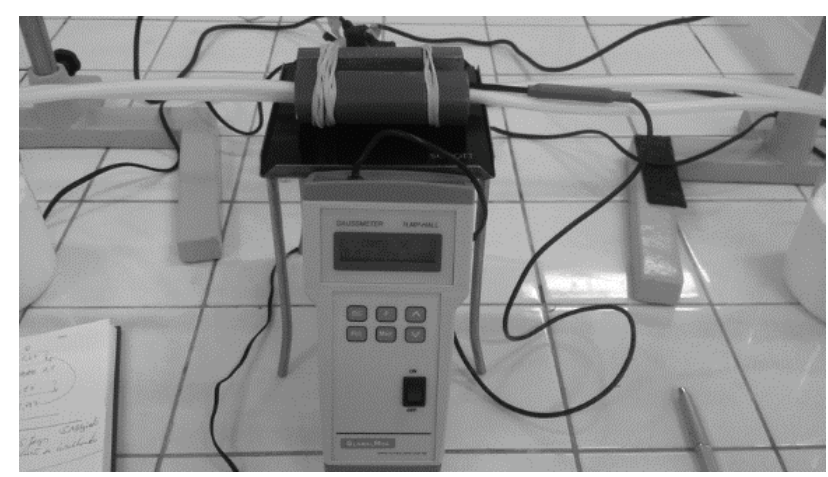

Figure 3: Magnetic conditioner. is 10 minutes, a part of the adhesive was separated for the application, without subjected to the magnetic conditioning process. The other portion of the adhesive was subjected to the magnetic conditioning process.

The magnetic conditioning was carried out in a system called magnetic cell according Figure 4 composed of the following components: two containers where the adhesive passed; two submerged centrifugal pumps (whose flow rate was $450 \mathrm{~L} / \mathrm{h}, 7 \mathrm{~W}$ power and 0.89 mwc of manometric cargo) silicone hoses to transfer the adhesive; magnetic conditioner (comprising a set of neodymiumiron-boron magnets). The intensity of the magnetic field presented a value of 2,120 Gauss $(0.02120 \mathrm{~T})$ measured by a Gauss meter and two micro processed agitators with a working speed of $50 \mathrm{rpm}$. The magnetic conditioning process was performed in 3 hours. Three hours is suggested time in studies on magnetic conditioning of water-based solutions. After such time, it was possible to proceed to the next step that it is the catalyzing of the adhesive. After that, the application of the adhesive in the substrates, with the union of them, denominated test specimens, was performed. Before application of the adhesive, the test specimens have been properly filed down and cleaned, as surface preparation procedure there. In the application of the adhesive, with and without the magnetic conditioning, a brush with soft bristles was used in the substrates.

The polymer matrix is responsible for the adhesion of the test specimens and their efficiency is measured by shear stresses. The catalyst used was Desmodur DN" (batch LDC 1300029), using 3\% of the formulated adhesive (Table 1) to start the curing process with a time of workability (pot life) of three hours, intensifying the process of coagulation and increasing the formation of the internal forces of the adhesive cohesion. That increased the mechanical properties mainly in the shear stresses of the studied adhesive. An antioxidant was added to the formulation to protect the polymeric matrix from the degradation of the adhesive and to maintain its validity term for marketing.

\section{Adhesive application in the substrates}

The formulated quantity was 3500 grams of the water based polyurethane adhesive and submitted to the processes as described in Groups 1 to 8. The adhesives were catalyzed with 3\% Desmoldur $\mathrm{DN}^{*}$ (batch LDC 1300029) on the total mass of each according to their respective groups. All adhesives were properly prepared and two coats were applied on all substrates, with a soft bristle brush, to compose Groups of 1 to 8, as already described above.

The test specimens were prepared in the dimensions of $200 \mathrm{~mm} \times$ $25 \mathrm{~mm} \times 3 \mathrm{~mm}$, with sticking area of $150 \mathrm{~mm} \times 25 \mathrm{~mm}$. It was analyzed an area of $25 \mathrm{~mm} \times 25 \mathrm{~mm}$, for each universe studied, according to Figures 5-7. All the substrates have had an open time by air drying in ambient air, by at least, twenty minutes before joining them.

All the PVC substrates were cleaned with the cosolvent COLABRAS ST (provided by Brascola company). After that, the formulated adhesive (Table 1) and following the process of distribution of the groups, already described above, and after about 20 minutes for the evaporation of water in ambient air, the adhesive was applied.

The application of water based polyurethane adhesive in the PVC substrates in which the test specimens were waiting for evaporation of the water fraction, in ambient air, during the drying process. At the end of water evaporation time in the PVC substrates, according to its groups, they were reactivated with the heated air using a thermal blower. Below the distribution of the applications process, according to the already mentioned groups. 
Citation: Costa W, Souza EMM, Silva LGA, Wiebeck H (2016) Behavior of Adhesion Forces of the Aqueous-Based Polyurethane Adhesive Magnetically Conditioned. Mod Chem Appl 4: 190. doi: 10.4172/2329-6798.1000190

Page 5 of 8

\begin{tabular}{|c|c|}
\hline Raw materials & Individual Quantity (\%) \\
\hline Dispercoll $\bigcup^{\circledR} 54$ & 98.0 \\
\hline Rhenofit DDA ${ }^{\circledR} 50$ EM & 2.0 \\
\hline
\end{tabular}

Table 1: Water based polyurethane adhesive formulation.

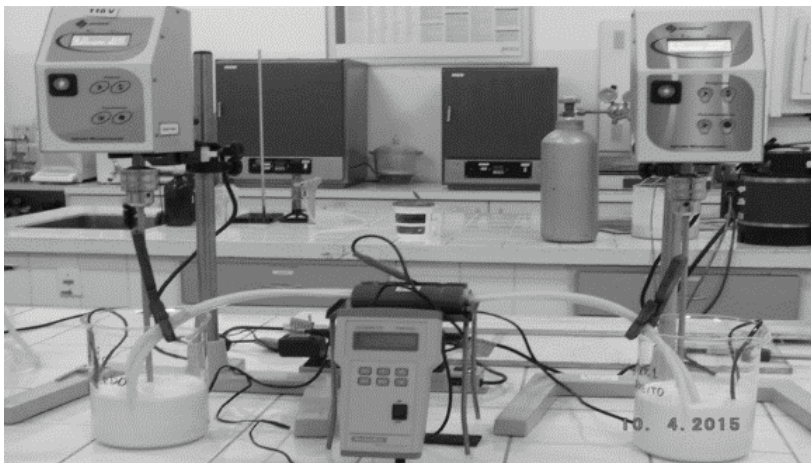

Figure 4: Magnetic cell.

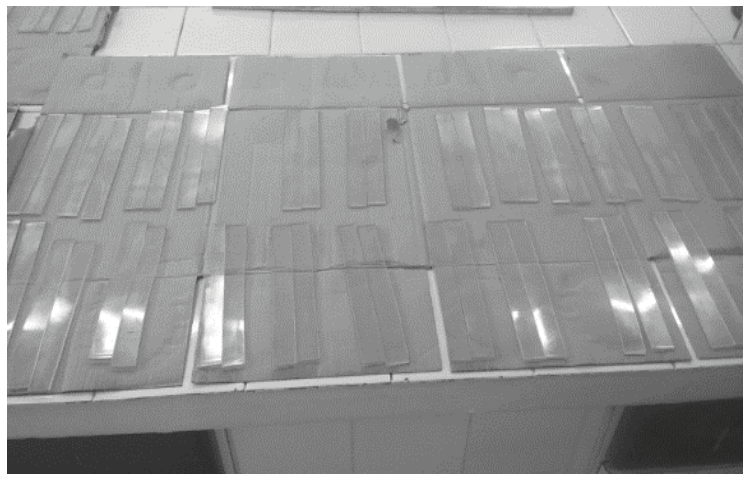

Figure 5: Preparation of the PVC substrate.

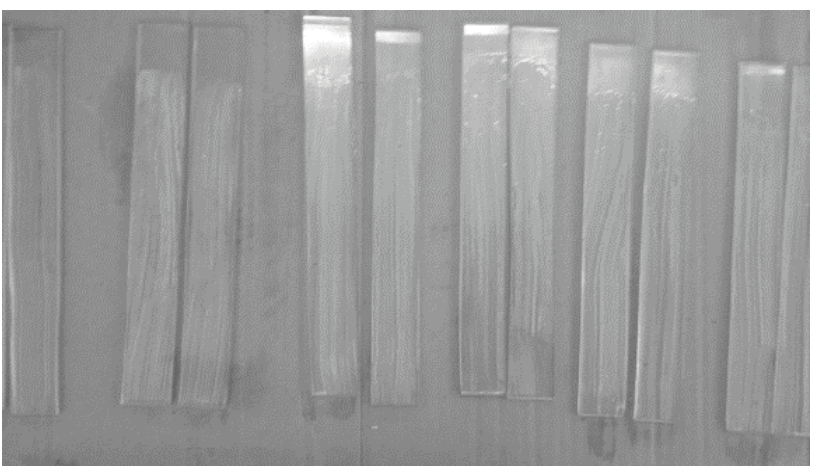

Figure 6: Adhesive applied in the PVC substrates.

After application of the adhesive in the groups 1 and 2, with soft bristle brush, we waited for the open time required of at least twenty minutes and the adhesive was reactivated with hot air at $60^{\circ} \mathrm{C}$, thus promoting union of the substrates with the application of pressure of $110 \mathrm{psi}$ for the bonding. They were cured for ten days and tested after $72 \mathrm{~h}$. The test specimens were subjected to tensile tests for determining the shear stresses to verify the adhesion capacity of the adhesive with the magnetic conditioning process. This step was performed with the intention of obtaining data for subsequent comparison between the current manufacturing processes and the new proposal with a magnetic conditioning demonstrated here.
In Groups 3 and 4 , the adhesive application procedure was with soft bristle brush, waiting for the open time of at least twenty minutes for the evaporation of water without reactivating it. Figure 6 shows the process of applying a quantity of hot air, at, at least $60^{\circ} \mathrm{C}$, for the reactivation of the adhesive and subsequent bonding of the test specimens. The groups from 5 to 8 the test specimens were also prepared for being subjected to non-ionizing radiation, in order to verify the shear stresses behavior and consequently the possible bond breaking in the substrate adhesion links in the material interface. It is emphasized that the bonding process obeyed the same process described by Groups 3 and 4 which had not had reactivation by heated air. The groups from 5 to 8 were cured for 10 days. After this period, the test samples were subjected to non-ionizing irradiation and performed the shear stresses tests after a period of 72 h. This study used an electron accelerator model DC1500/25/4 JOB188 (Dynamitron $^{\circ}$ ), with an energy of $0.5 \mathrm{MeV}$ and $1.5 \mathrm{MeV}$, a beam current $25 \mathrm{~mA}$, scanning from 60 to $120 \mathrm{~cm}$ with a maximum power of $37.5 \mathrm{~kW}$ beam. Though the dose rate can vary from $1.07 \mathrm{kGy} / \mathrm{s}$ to $161.67 \mathrm{kGy} / \mathrm{s}$, the test specimens were irradiated with doses of 15 and $25 \mathrm{kGy}$. The experiment was limited to $25 \mathrm{kGy}$, because above such value the process will be economically impracticable. The test specimens were irradiated in a direction perpendicular to the substrate polyvinyl chloride (PVC) surface. The electron energy range was selected to allow maximum penetration of the electron beam through the PVC plates, because in this region of power PVC braking was small $(1.779 \mathrm{MeV} \mathrm{cm} / \mathrm{g})$, and the electrons reach the adhesive cured in the substrates (PVC). The irradiation was performed in atmospheric air (atmosphere). In order to evaluate the behavior of the adhesive forces on the test specimens, the tests of shear stresses were conducted using a universal tensile testing machine (Instron, model 3367, with a $30 \mathrm{kN}$ load cell), complimentary Brascola company. In the discussion of the following results, all the groups from 1 to 8 waited ten days to the curing process and more $72 \mathrm{~h}$ to start the shear stresses tests, with the purpose to make sure that the curing process would not interfere in the tests results.

After the adhesive total cure all the test specimens were submitted to the shear stresses test, including the irradiated samples. The standard used to test the shear stresses was ASTM D-1002 [Standard Test Method for Apparent Shear Strength of Single-Lap-Joint adhesively Bonded Metal Specimens by Tension Loading (Metal-to-Metal)], adapted for PVC substrates with PVC.

\section{Results and Discussion}

\section{Viscosity}

It is found that the initial viscosities of water based polyurethane adhesives as well as the formulation without magnetic conditioning that currently exist on market is $350 \mathrm{mPa}$.s. In this research with the magnetic conditioning process technique, the viscosity of the formulated adhesive was increased to $1100 \mathrm{mPa}$.s.

Therefore, a significant thickening of the water-based adhesive, leaving it with the viscosity closer to that of the commercial solvent based polyurethane adhesives that is about $2000 \mathrm{mPa}$.s. No type of thickener was added to the formulation of the adhesive to raise its viscosity. The only differential was the magnetic conditioning process.

\section{Shear stresses}

Regarding the adhesion capacity, the results of shear stresses tests for non-irradiated samples are presented in Table 2. Figures 8 and 9 present the results of the shear stresses of the substrates, the adhesive with and without magnetic conditioning; have shown different behaviors in the adhesion forces. These results were compared with the 
Citation: Costa W, Souza EMM, Silva LGA, Wiebeck H (2016) Behavior of Adhesion Forces of the Aqueous-Based Polyurethane Adhesive Magnetically Conditioned. Mod Chem Appl 4: 190. doi: 10.4172/2329-6798.1000190

Page 6 of 8

\begin{tabular}{|c|c|c|c|c|}
\hline \multicolumn{5}{|c|}{ Water-base } \\
\hline \multicolumn{5}{|c|}{ Groups } \\
\hline & 1 & 2 & 3 & 4 \\
\hline Test Specimen & $\begin{array}{l}\text { Without magnetic conditioning } \\
\text { with reactivation (SCMR) }\end{array}$ & $\begin{array}{c}\text { With magnetic conditioning with } \\
\text { reactivation (CCMR) }\end{array}$ & $\begin{array}{l}\text { Without magnetic conditioning } \\
\text { without reactivation (SCM) }\end{array}$ & $\begin{array}{l}\text { With magnetic conditioning } \\
\text { without reactivation (CCM) }\end{array}$ \\
\hline Reactivation & at $60^{\circ} \mathrm{C}$ & at $60^{\circ} \mathrm{C}$ & - & - \\
\hline 1 & 3.73 & 3.35 & 3.84 & 4.89 \\
\hline 2 & 4.88 & 1.99 & 5.34 & 5.67 \\
\hline 3 & 4.32 & 2.83 & 5.30 & 5.78 \\
\hline 4 & 4.84 & 3.32 & 5.83 & 5.80 \\
\hline 5 & 3.78 & 3.02 & 2.45 & 4.80 \\
\hline 6 & 3.88 & 3.16 & 4.53 & 5.90 \\
\hline 7 & 3.71 & 1.35 & 3.18 & 5.67 \\
\hline 8 & 3.90 & 2.29 & 3.43 & 5.77 \\
\hline 9 & 3.23 & 5.03 & 2.23 & 5.85 \\
\hline 10 & 4.70 & 4.45 & 2.74 & 5.92 \\
\hline 11 & 4.13 & 3.72 & 3.18 & 5.89 \\
\hline 12 & 3.71 & 3.44 & 3.16 & 6.03 \\
\hline 13 & 4.27 & 2.15 & 4.62 & 5.87 \\
\hline 14 & 4.58 & 2.09 & 4.18 & 6.11 \\
\hline 15 & 4.60 & 3.02 & 3.20 & 5.96 \\
\hline 16 & 3.83 & 2.10 & 2.72 & 6.45 \\
\hline 17 & 2.93 & 1.30 & 2.28 & 6.30 \\
\hline 18 & 4.88 & 4.35 & 4.91 & 5.87 \\
\hline 19 & 3.50 & 3.79 & 2.31 & 6.33 \\
\hline 20 & 4.38 & 1.48 & 4.33 & 6.39 \\
\hline 21 & 4.01 & 2.29 & 3.01 & 6.29 \\
\hline 22 & 4.80 & 3.93 & 2.92 & 5.86 \\
\hline 23 & 4.47 & 1.88 & 2.10 & 6.36 \\
\hline 24 & 4.80 & 2.06 & 1.91 & 6.39 \\
\hline 25 & 4.67 & 2.79 & 1.91 & 6.42 \\
\hline Average & 4.18 & 2.85 & 3.42 & 5.94 \\
\hline
\end{tabular}

Table 2: Results of traction Tests - Shear Tension in $10^{5} \mathrm{~Pa}$.

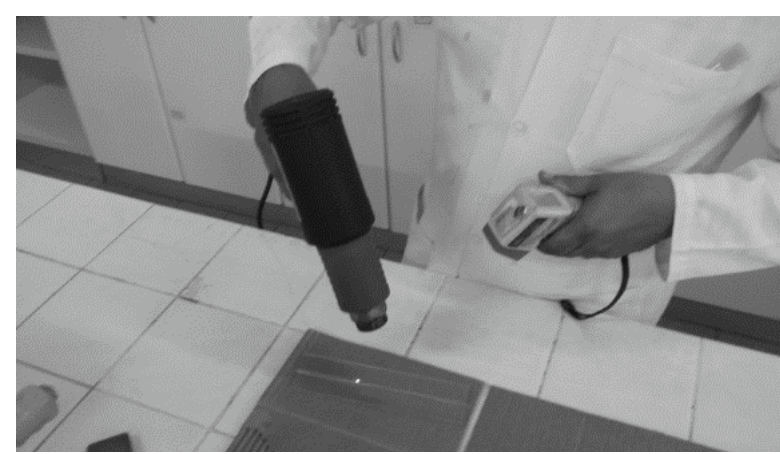

Figure 7: Thermal reactivation of the test specimens.

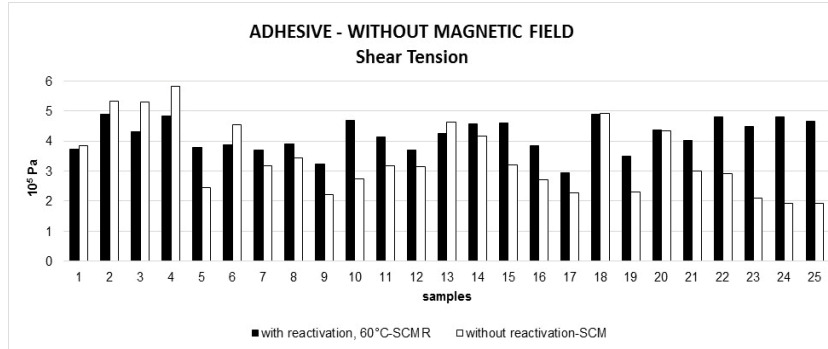

Figure 8: Tensile test results for Group 1, without magnetic conditioning and reactivated at $60^{\circ} \mathrm{C}$ and for Group 3, without the magnetic conditioning and no reactivation with heated air. second step of this work, as shown in Table 3, Figures 10 and 11. The test specimens was submitted to non-ionizing irradiation where it was possible to evaluate the behavior of shear stresses of the formulated adhesive and also evaluate the effect of the magnetic field on it. To facilitate the visualization of the behavior of shear stresses supported by test specimens from de two universes of samples, without magnetic conditioning and with reactivation at $60^{\circ} \mathrm{C}$, according to Figure 7 , It is observed that the values of the shear stresses of the adhesive formulated without magnetic conditioning and with reactivation by heated air were rather close. Even so the average value of $4.18 \times 10^{5}$ $\mathrm{Pa}$, for reactivated test specimens was $22 \%$ higher than in the nonreactivated ones, whose average value was $3,42 \times 10^{5} \mathrm{~Pa}$. The results of shear stresses, supported by two universes of test specimens with field and without and reactivation at $60^{\circ} \mathrm{C}$, Figure 8 below it is observed that the behavior of the adhesive shear stresses formulated with magnetic conditioning, without reactivation, the average value is $5.94 \times 10^{5} \mathrm{~Pa}$, higher compared to the magnetically conditioned and reactivated heated air at $60^{\circ} \mathrm{C}$, showing an average value of $2.8510^{5} \mathrm{~Pa}$. With this it was possible to increase the adhesion of the water based polyurethane adhesive for significant values, without thermal reactivation by heated air. The only difference in the production process was the magnetic conditioning. Regarding the magnetic conditioning, the magnetic field changed the size of micelles of the polymeric matrix, in which was found an increase of the viscosity and shear stresses. In the application process, when activated by heated air, the adhesive magnetically conditioned, loses property in the values of shear stresses due to magnetic disorientation provoked by the heating (hot air). Therefore, when the thermal energy is not applied, the shear stresses values exceed 
Citation: Costa W, Souza EMM, Silva LGA, Wiebeck H (2016) Behavior of Adhesion Forces of the Aqueous-Based Polyurethane Adhesive Magnetically Conditioned. Mod Chem Appl 4: 190. doi: 10.4172/2329-6798.1000190

Page 7 of 8

\begin{tabular}{|c|c|c|c|c|}
\hline \multicolumn{5}{|c|}{ Water-Base } \\
\hline \multicolumn{5}{|c|}{ GROUPS } \\
\hline & 5 & 6 & 7 & 8 \\
\hline Type of exposition I & $\begin{array}{l}\text { Without Magnetic conditioning } \\
\text { (SCM) }\end{array}$ & $\begin{array}{l}\text { With Magnetic conditioning } \\
\text { (CCM) }\end{array}$ & $\begin{array}{l}\text { Without Magnetic conditioning } \\
\text { (SCM) }\end{array}$ & $\begin{array}{l}\text { With Magnetic conditioning } \\
\text { (CCM) }\end{array}$ \\
\hline Type of exposition I I (dose) & 15 kGy & 15 kGy & $25 \mathrm{kGy}$ & 25 kGy \\
\hline Test Specimen & & Shear Tension & & \\
\hline 1 & 1.49 & 6.27 & 1.96 & 0.56 \\
\hline 2 & 3.68 & 7.45 & 0.67 & 0.63 \\
\hline 3 & 3.68 & 6.77 & 2.26 & 0.77 \\
\hline 4 & 2.64 & 9.35 & 1.37 & 0.30 \\
\hline 5 & 4.57 & 7.14 & 1.32 & 0.28 \\
\hline 6 & 3.66 & 5.70 & 2.79 & 0.84 \\
\hline Average & 3.29 & 7.11 & 1.73 & 0.57 \\
\hline
\end{tabular}

Table 3: Results of Traction Tests -Shear Stresses $10^{5} \mathrm{~Pa}$ - irradiate samples.

the reactivation by heating processes currently utilized. It is observed in the values shown in Group 1 (Table 2), which represents the product currently used in the market.

Regarding the adhesion capacity, the results of the shear stresses tests for irradiated samples are shown in Table 3: To facilitate the visualization of the behavior of shear stresses supported by the irradiated test specimens, from two universes of samples, without and with the magnetic conditioning (Figures 10 and 11). Figure 10 Tensile test results, for the Group 5 without reactivation, without magnetic conditioning and irradiated to $15 \mathrm{kGy}$; Group 6 without reactivation, magnetic conditioning and irradiated to $15 \mathrm{kGy}$. It was observed thus, that the adhesive shear stresses formulated without magnetic conditioning (Group 5), without reactivation and irradiated at $15 \mathrm{kGy}$, presented average value of $7.11 \times 10^{5} \mathrm{~Pa}$. In relation to conditioning magnetically (Group 6), without reactivation, and irradiated at $15 \mathrm{kGy}$ which presented an average value of $3.29105 \mathrm{~Pa}$. The samples irradiated at $25 \mathrm{kGy}$, without reactivation magnetic conditioning and without (Group 7), presented an average value of $1.73 \times 10^{5} \mathrm{~Pa}$. Regarding the magnetically conditioning (Group 8 ), without reactivation and irradiated at $25 \mathrm{kGy}$, which presented an average value of $0.57 \times 10^{5}$ Pa) [22].

\section{Conclusions}

Based on this research work, we can verify the behavior of the adhesion strengths submitted by shear stresses in the waterbased polyurethane adhesive, under the effect of the magnetic field. Regarding the adhesiveness, it was evident the possibility of increment it with the magnetic conditioning. Comparing the results of the shear stresses tests, of the four groups of initial test specimens, we succeed to approach the result of adhesion capacity, compared with a solventbased polyurethane adhesive produced currently in the market. The studied formulation proved efficient after the magnetic conditioning and without reactivation which also generated a significant alteration of the viscosity. The variation is increased from $350 \mathrm{mPa}$.s to 1100 mPa.s, without being necessary to add any other product as a thickener. Therefore, the new concept of the process of water based polyurethane adhesive manufacturing conditioning magnetically, in which the thermal reactivation is not required to promote the union of the substrates, confers adequate properties for this type of adhesive, making it competitive on the market compared with the application process. If the adhesives with the same formulation with magnetic conditioning and without reactivation were compared with an adhesive without magnetic conditioning and reactivation, the increase in the adhesion capacity was of $42.11 \%$ with those magnetically conditioning

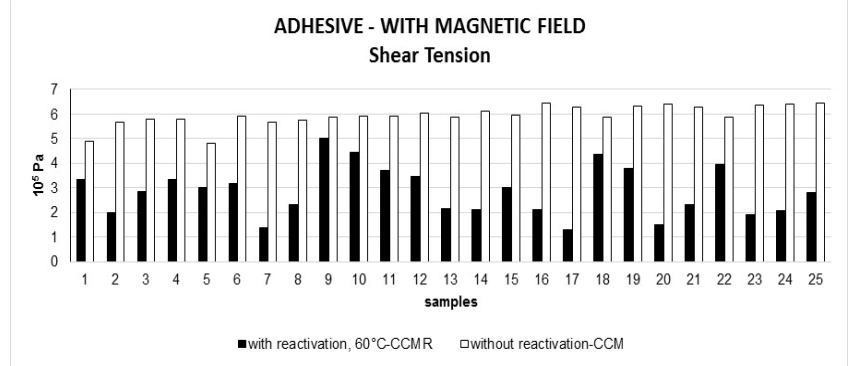

Figure 9: Tensile test results for Group 2, with magnetic conditioning and reactivated at $60^{\circ} \mathrm{C}$ and Group 4 , with magnetic conditioning and without reativation by heated air.

\section{ELECTRON BEAM IRRADIATION - 15 kGy}

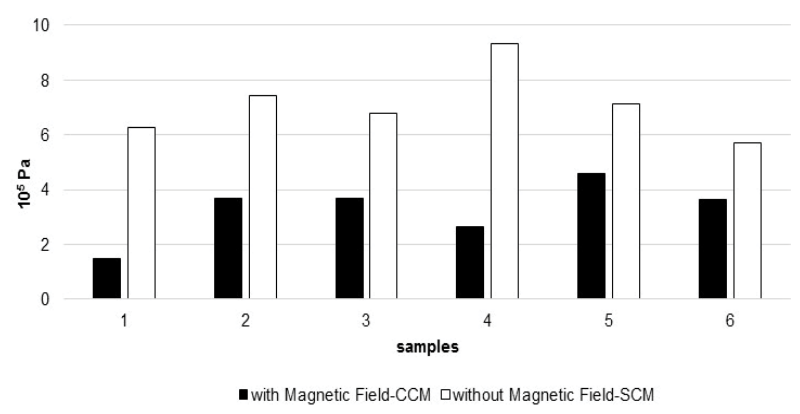

Figure 10: Tensile test results, for the Group 5 without reactivation, without magnetic conditioning and irradiated to $15 \mathrm{kGy}$; Group 6 without reactivation, magnetic conditioning and irradiated to $15 \mathrm{kGy}$.

adhesive. The result was far beyond expectations, without any insertion of other raw materials such as, for example, addition of resins to improve adhesive adhesion characteristic. It was observed when there is a magnetic conditioning and the test specimens were submitted to non-ionizing irradiation, regardless the dose, in the tests of the final four groups, the adhesion decreased. If we verify the shear stresses at the adhesive without reactivation, without magnetic conditioning and irradiated at $15 \mathrm{kGy}$ and found an average value of $3.2910^{5} \mathrm{~Pa}$ in the shear stresses tests, i.e., 2.16 times lower compared to the average value found in the test specimens with magnetically conditioned and without reactivation, which was of $7.1110^{5} \mathrm{~Pa}$. When a non-ionizing irradiation dose of $25 \mathrm{kGy}$ was applied, the shear stresses decrease considerably, 


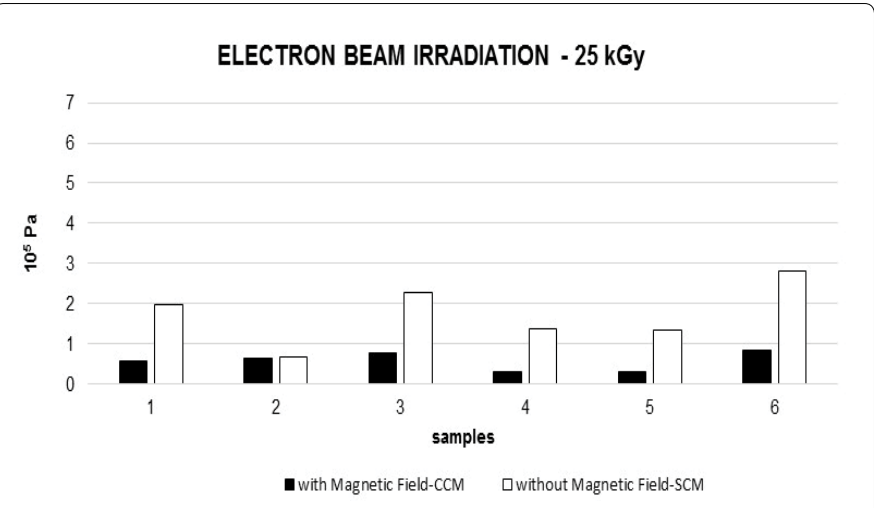

Figure 11: Tensile test results: For the Group 7 without reactivation, without magnetic conditioning, irradiated at $25 \mathrm{kGy}$ and Group 8 without reactivation, with magnetic conditioning and irradiated at $25 \mathrm{kGy}$.

regardless the process, with or without magnetic conditioning, and have as a consequence, the breaking of the bonds of the polymeric matrix on the test speciments interface. Those adhesives formulated in this work, with magnetic conditioning and without reactivation by heated air, presented the best adhesion capacity in the application process. Because when submitted to heat air, all the acquired magnetic information is lost, thereby decreasing its efficiency in shear stresses and compromising the adhesion of these test specimens. For the production process it is possible to use magnetic conditioning, in which we will have the best result of shear stresses without the need for reactivation of the adhesive by heated air (heat), to carry out the bonding of the substrates in the preparation of the test specimens. This process innovates the system of production of water based polyurethane adhesives, thereby saving thermal energy which reduces the manufacturing costs of operation, making the final product (shoes, belts, bags and similar) more competitive as well as being ecologically friendly. However, the difference in the production process was the magnetic conditioning, more effective without reactivation for heat, in the application of the adhesive. In the future others water based adhesives families can be studied, such as acrylic, polyvinyl chloride, polyvinyl acetate, among others.

\section{Disclosure Statement}

No potential conflict of interest was reported by the authors.

\section{Acknowledgments}

Our special thanks to the company Brascola, Convestro, Evonik, Rhein Chemie Rheinau. The Professor Dr. Hélio Wiebeck, the Professor Dr. Leonardo Gondim de Andrade Silva, Departamento de Tecnologia das Radiações-IPEN (Instituto de Pesquisas Energéticas Nucleares). The Dra. Vanessa C. Loureiro and the Professor Dra. Esther Galvão.

\section{References}

1. Petrie EM (2007) Handbook of Adhesives and Sealants. 2nd edn. McGraw-Hill, New York, USA.

2. Pizzi A, Mittal KL (2003) Handbook of Adhesive Technology. 2nd edn. Marcel Dekker Inc., New York, USA.

3. Skeist I (1989) Handbook of Adhesives. 3rd edn. Van Nostrand Reinhold Co., New York, USA.

4. Liesa F, Bilurbina L, Marcombo SA (1990) Adhesivos Industriales. Barcelona.

5. Belova V (1972) Magnetic treatment of water. Soviet Science Review: Scientific Developments in the USSR. Moscow. n.3.

6. Kronenberg JK (1987) Magnetic Water Treatment Demystified Magnets. Paper Courtesy of Teldon of Canada Ltd., pp: 150-156.
7. Landgraf FJG, Garcia PMP, Poço JG, Giulietti M (2004) Effect Magnetic Field in Aqueous Solutions. In: XVI Brazilian Engineering and Materials Science Congress.

8. Lambert K (1999) Study of factors related to magnetic treatment of calcium carbonate saturated water. Provo (EUA): Brigham Young University, Department of Civil and Environmental Engineering.

9. Costa W (2006) Contribution to the study of the magnetic conditioning of water for industrial purposes. Dissertation, São Paulo BR School University Center of Mauá.

10. Souza EMM (2015) Contact adhesive polychloroprene water-based nano additivated conditioning and magnetically, Thesis. São Paulo (BR) Polytechnic School of the University of São Paulo.

11. Costa W (2012) Behavior of the adhesion forces of silicone adhesive sealant and butyl mastic under the effect of ionizing radiation. Polytechnic School of the University of São Paulo. Department of Metallurgy and Materials.

12. Brazilian Association Industry Chemistry (2011) Statistics segment of glues adhesives and sealants. 10: 1-19.

13. Calpena EO, Ais FA, Palau AMT (2009) Influence of the chemical structure of urethane-based thickeners on the properties of waterborne polyurethane adhesives. The Journal of Adhesion 85: 665-689.

14. Limiñana MAP, Aís FA, Palau AMT (2007) Influence of the hard-to-soft segment ratio on the adhesion of water-borne polyurethane adhesive. Journal of Adhesion Science and Technology 218: 755-773.

15. Souza MME, Costa W, Silva LG (2016) Behavior of adhesion forces of the aqueous-based polychloroprene adhesive magnetically conditioned. Journal of Adhesion Science and Technology.

16. Costa W, Wiebeck H, Martinelli JR (2012) Improved Adhesion of Butyl Mastic Using Electron Beam Irradiation. Journal of Adhesion Science and Technology 26: 1699-1704.

17. Keberle W, Oertel G, Bayer AG (1970) Anionic polyurethane dispersions and a process for the production thereof. United States Patent US 3,539,483A.

18. Hombach R, Reiff $H$, Wenzel W, Bayer AG (1984) Aqueous adhesives containing water-dispersible polyisocyanate preparations. United States Patent US 4,433,095A.

19. Maksymkiw M, Haider G, Dochniak MHB (1997) Fuller Licensing \& Financing Inc., Water-based adhesive formulation having enhanced characteristics. United States Patent US 5,624,758A.

20. Sagiv E (1997) Olin Corporation. Water-based urethane adhesive. United States patent US 5,688,356A.

21. Bayer (2015) Leverkusen: Coatings, Adhesives and Specialties.

22. Zenner MD, Madbouly SA, Chen JS (2015) Unexpected tackifiers from isosorbide. Chem Sus Chem 83: 448-451. 